\title{
Integrating ICT into Teaching Foreign Languages for Future Mining Engineers as a Factor of Mining Industry Innovative Development
}

\author{
Natalia Godzhaeva ${ }^{1}$, Timur Logunov ${ }^{1, *}$, Marina Lokteva ${ }^{1}$, and Pavel Strelnikov ${ }^{2}$ \\ ${ }^{1}$ Kemerovo State University, 6500006 Krasnaya Ulitsa, Kemerovo, Russia \\ ${ }^{2}$ T.F. Gorbachev Kuzbass State Technical University, 65000028 Vesennya st., Kemerovo, Russia
}

\begin{abstract}
The Kemerovo Region is the leading coal cluster of Russia and Europe, where about $60 \%$ of all domestic coal is mined, 42 mines and 51 open-pit mines are operating, as well as 54 coal processing plants and installations. At the beginning of 2019, more than 90 thousand people worked in the coal industry of Kuzbass. The task of increasing the labor productivity of coal enterprises is largely determined by personnel potential, which is the main productive force in the post-industrial era. Enterprise staff is the creator of all the material and intellectual values of the coal industry, without exception. Today, the maximum use of all available internal production resources depends on the quality of university training of miners, the formation of their professional and communicative competences. This study focuses on the use of new technologies in learning foreign language by future mining engineers. It discusses a variety of attitudes and incentives which support the readiness of students in this field to increase their learning skills through using ICT. In this paper, the authors review practices and experience of using the technology in classroom summarized in expert opinions of foreign language teachers working with undergraduate students - future mining engineers.
\end{abstract}

\section{Introduction}

Within the national fuel and energy complex as a whole, the domestic coal industry has a number of competitive advantages due to the presence of huge reserves of coal, providing Russia with the 2 nd place in the world in terms of mineral deposits. This circumstance is a competitive factor in the possibility of entering the world market.

The presence of significant experience in the use of this energy source and the improvement of the sustainability of energy supply contributes to the adaptation of the domestic coal industry to changing market conditions, including the crisis situations and the realities of cyclical economic growth. Moreover, significant reserves of increasing the efficiency of production capacities determine the possibility of using the variety of different

*Corresponding author: tlogunov@,mail.ru 
types of coal products, especially in the integration processes associated with the priority directions of innovative development of the economy.

At the same time, there is the weak point in Kuzbass coal industry innovative development - the shortage of modern qualified personnel, since the regional education system cannot fully meet the needs of employers. In accordance with the development strategy of Kuzbass, by 2025 the coal production will increase by $30 \%$ and processing volumes by $40 \%$, while a decline in the number of graduates of mining specialties is predicted.

No less relevant is the problem of improving the quality of mining engineers' training for modern coal industry, which innovative development is the decisive factor of the adaptation of the international experience of high-performance and environmentally friendly technologies. This actualizes the formation of the communication competence of future mining engineers at the stage of their university training. Therefore, there is a need for such a way to organize the process of training future mining engineers in professional disciplines as well as on foreign languages, which would encourage integrating educational tools that contribute to the successful development of professional and communicative competencies [1]. One of the roles of ICT in teaching a foreign language is to provide the tools to facilitate students' development within the existing English curriculum.

However, the reality of the teaching-learning process at T.F. Gorbachev Kuzbass State Technical University is not so idyllic. Although many students of the University have been learning English for at least eight years, on average, their level is not higher than elementary. In other words, there is a need for innovative educational technologies that should increase involvement of learners in independent work, decrease their possible dissatisfaction and stress caused by slow progress in learning and create flexible conditions for every learner.

\section{Materials and Methods}

In this study, ICT is defined as a "diverse set of technological tools and resources used to communicate and to create, disseminate, store and manage information. These include computers, internet and other new technologies" [2]. Many studies have indicated that the use of ICT in foreign language classrooms can enhance language learning in terms of promoting authentic text-based language communicative learning environment [3].

Learning with ICT has potential to provide a "rich linguistic environment" which is the key to language learning [4]. By using hyperlinked text with its multimedia integration and the visual properties, the learners can increase awareness of language features. Digital tools make it possible for students to be more active learners. Students can also use the internet for self-study purposes without the need for constant teacher's control.

By using such Internet-based and communication technologies to communicate with fellow students around the world, and engage in conversations with experts in their field, teachers and learners can bridge the gap between the classroom and workplace demands.

Language learning is a complex cognitive task. From this point of view, language learning with ICT can be viewed as a cognitive interaction, which enables teachers to create text reconstruction activities, and learners to create a mental representation of the target language [5].

Collaboration is another key component of language learning with technologies. In collaboration, the capacity of learners to learn from the experiences of their peers is emphasized. Foreign language learners in a collaborative environment use language to express opinions connected to reaching the goal to others in their group in spoken or written language, and listen to or read the opinions of other members [6]. 
However, without the guidance of a teacher, only the most motivated and perhaps those who already have a higher level of English will be able to make good use of the resources available in order to improve their language skills. Teachers should adapt the applications and websites to their teaching and learning contexts [7].

The use of ICT in teaching and learning language also brings impact on changing literacy in today's classroom. Four types of literacy as essential to success were identified: Digital, Art, Oral and Written. Teachers and researchers agree that the ability to present oneself in spoken and written digital format is increasingly an expected part of academic work.

Despite the positive impact reported in these studies, the use of technology in teaching and learning has its problems and challenges. For example, technology has been said to encourage student laziness since it makes it easy for them to take short cuts and not put effort into their writing; they often 'copy and paste' and download material from the internet without acknowledging sources [8].

The paper discusses some key issues concerning the methodological foundations of integrating Internet technologies in teaching foreign languages, namely: conditions, methods and forms in the language educational process, as revealed in expert opinions.

\section{Materials and Method}

Discussion of the above issues and analysis of the material are based on the assumption that the application of ICT means and tools in foreign language education of future mining engineers involves some peculiarities which make it beneficial both in terms of comparatively higher learners' preparedness/readiness to use it and multiple literacies developed through it (not only specific use of a foreign language but also more general social and communicative competences); at the same time, involving ICT in teaching English for professionals in this filed poses a number of related challenges.

The present research uses a multimethod approach and summarizes the experience of teaching foreign languages for the future professionals in mining industry in a Russian higher institution obtained from expert interviews with university teachers of foreign languages. Expert opinions of 24 lecturers (each of them having more than 5 years experience of teaching in a university) were submitted in writing anonymously and later analyzed.

The authors reviewed publications on the problems of teaching English at higher educational institutions; analyzed (including content analysis) the practice and experience of teaching English for future mining professionals at Kemerovo universities; and evaluated the methodology of ICT application in foreign language education at Russian universities.

\section{Results and Discussion}

Characterizing the foreign language education at non-linguistic departments of Kuzbass higher educational institutions in general it is necessary to note the lack of uniform approach to organizing the process, resulting in diversity of total academic hours and constant attempts to redesign the content and concept of the working programmes as a response to changes in educational standards enacted by the Ministry of Higher Education and Science in Russia. The variety of foreign language learning is explained by different factors. Curriculum structure at the higher educational institutions of the Russian Federation presupposes General English course for the first-year students and more advanced ESP course for the $2^{\text {nd }}$ or $3^{\text {rd }}$ year students of non-linguistic fields of training. The definition of learning outcomes is also complicated for a lecturer responsible for curriculum 
planning because it is to describe the so called competence-based results (outcome) of the development of certain linguistic knowledge, abilities and skills enabling a learner to organize everyday communication or (after learning an ESP course) professional activity in a foreign language. There is a noticeable regional gap in the educational infrastructure (e.g., teaching facilities and instructional equipment), which, in turn, further deepens the existing variation in learning and organizational practices such as curricula, teaching aids, teaching approaches and methodologies and syllabi. Such a situation makes it more difficult for English language teachers to implement technology-enhanced language teaching.

ESP classes include conscious activity stimulating intellectual development, speech practice and project work. Introducing new technologies in language teaching means formation of the multimodal communicative competence (video, audio, non-verbal means of presenting a teaching material, certain organization of room space and communication via Internet). Such concept helps students to articulate their ideas during speech practice, writing exercises, express some information through non-verbal communication during different role plays, understand complex plans, use different media and technological facilities, compose statements, make decisions, cooperating with other participants of learning process. This format makes the work flexible, adaptive, innovative, practiceoriented and proves the significance of the pedagogy for the present-day labor market situation, developing inner-motivation of a lecturer.

All experts share the conviction that languages are best learnt and taught by means of interaction and that language learning is supported by social interaction between learners, teachers and their communicative partners outside classroom. Reflecting on the fact that all tools mediate student's experiences in one way or another, overwhelming majority of experts mentioned such tools can become a medium for enriching the learner's contact with the language. So it is important to consider that in many cases students' interactions with technology tools are similar to real-life interactions because they are social and natural [9]. To do so, the information delivered by ICT tools must be relevant to learner special needs. By offering students such materials, class discussions via e-mail, use of social network can enhance learner interest and increase interaction with peers and tutors.

It is essential that the experts interviewed shared several points regarding specific benefits of ICT tools and format for teaching future engineers in addition to those commonly established by researchers. Namely, using ICT was reported as a powerful facilitating media and a tool expanding learners' opportunities in studying foreign languages.

Lecturers of T.F. Gorbachev Kuzbass State Technical University stated that computerbased and internet-based learning tools are potentially more beneficial for their students as learners are more willing and better trained to employ technical means in various educational formats: classroom work, distance and independent studies. While students of humanities would often prefer person-to-person off-line format of interaction as the respondents observed. In other words, technical (ICT) means is a more natural way to deal with learning materials for future engineers than conventional means (especially, in comparison with student-teacher classroom talk in classroom).

Another commonly observed strength of IC technological means of teaching foreign languages is greater flexibility and independence in learning process provided for learners. The fact is many students in the Russian higher educational institutions find it challenging to combine regular preparation for classes with part-time job and experience anxiety about reporting and responding in class when they are underprepared. Using remote platforms and online media of communication with teachers they can overcome such stressful factors. Moreover, many experts emphasize the fear of making mistakes as a particular feature of adult Russian learners of foreign languages (sometimes it is described as broadly as a trait of national Russian mentality, however, the authors prefer to abstain from such 
overgeneralizations hard to prove). Thus, ICT-based remote format allows learners to overcome fears of public reporting in a foreign language which is no doubt stressful it itself.

It was expected that the respondents would not miss pointing out the strength of computer-based and online-based technologies in equipping learners with more up-to-date and diverse learning resources. This is not only making the learning process more exciting and attractive for students but also is a crucial requirement of training a professional in mining engineering as mastery in using information search and access technologies (primarily, in English) enables him/her to access most recent information about developments in this field.

An essential advantage of broader application of online and media technologies in both classroom and independent foreign language learning is the possibility of developing multiple competencies (literacies). Mastering any language is not a goal in itself but a means of achieving goals of everyday or professional communication. Therefore, forming and upgrading purely linguistic competence learners are improving their level of accompanying competencies. Digital literacy, already formed in students of mining engineering field, acts beneficially to improve their skills of social interaction through language learning based on online and social media tools. It goes without saying that proficiency in cross-cultural communication, networking etc. is no less essential for future professionals in engineering that in humanities. While our experts - teachers of Mining Department - note that their learners are less confident in it, they stress the unprecedented potential of ICT-based technologies for dealing with this challenge.

At the same time, the respondents spoke about their doubts and concerns regarding the broader use of ICT in learning foreign languages. The challenges identified can be grouped as follows:

- potential and observed weaknesses of ICT-based learning,

- methodological challenges for teachers,

- the need for extra support for learners.

The most frequently observed points in the first category were overdependence of learners on technologies, limited possibilities for controlling and evaluating students' progress and reduction in uniformity of the learning outcomes, not to mention the expected fall in final results. To sum up, lecturers expressed their concerns about possible substitution of using ICT as a means and tools of mastering a language for modern technologies as a means of avoiding challenges and complexities in learning (e.g., using machine translating technology instead of learning actual language units), which can result in even worse learning outcomes. At the same time, university lecturers presume that learning process is becoming less controlled by them.

Moreover, a great proportion of experts noted the need for major changes in methodology of organizing classroom and independent activities for students, which is closely connected with a more general change in teachers' attitudes and the need for specific training for teachers. This demonstrates a realistic approach of many teachers who are aware of the necessity of introducing many changes in teaching/learning process with less classroom work and more remote independent activities. In addition, this requires massive shifts in the forms and scopes of learning activities and new teaching aids. As a result, a serious degree of courage and willingness to undertake such extensive work is expected from foreign language lecturers. Needless to say, that this circumstance may serve as a serious hindrance on the way of broader introduction of ICT.

Finally, foreign language lecturers recognize the need for special guidance and/or specialized training for efficient use of ICT in teaching/learning of foreign languages. A number of experts interviewed noted that the diversity of on-line learning materials available for independent studies can confuse even a relatively experienced learner, many 
of the free distributed content being of insufficient quality. Hence, students, however experienced they are in the use of technology, need teacher's assistance in evaluation of the quality of learning materials (software tools, aids, on-line resources). Teachers themselves sometimes lack essential skills for dealing with a variety of learning platforms, software, and digital teaching aids. Some experts reported their willingness to update their proficiency and to learn the relevant experience and best practices of their colleagues who succeeded in incorporating ICT formats and tools in their teaching process.

It should be stressed that teachers' awareness of the prospective challenges in applying ICT tools and recognition of the necessity of further guidance to cope with them seem to be inspiring factors. If foreign language lecturers of T.F. Gorbachev Kuzbass Technical University realize the need for special approach to deal with the issue in detail and are ready to search for solutions, then they are positive on introducing more IC-oriented and online-based technologies in their practice.

\section{Conclusion}

The analysis of responses of lecturers at T.F. Gorbachev Kuzbass State Technical University shows that most foreign language lecturers teaching future mining engineers are aware of the possibilities and usefulness of ICT in teaching a foreign language. It is undeniable that teaching resources and materials provided online are more updated and teachers can refer to it in order to design more interesting and engaging lesson for students. ICT can be considered as independent and effective resource for self-study which encourages development of multiple professional and linguistic competencies. Based on the expert opinions obtained we admit that foreign language instructors can use ICT resources as additional materials in teaching a foreign language and/or even in teaching a special course (module) in a foreign language. The teaching goal in this context is using the original material in language practices for satisfying the specific needs of mining engineering students at T.F. Gorbachev Kuzbass State Technical University.

\section{References}

1. J. Bloch, M. Wilkinson, Teaching digital literacies. (TESOL Publications, Alexandria, 2014)

2. M. Ellis, M. Wilkinson, M. Vallance, Teaching English to Chinese ESL students: Classroom practices. (Pearson, Singapore, 2005)

3. J. Ohler, EL, 66, 6 (2009)

4. K. Purcell, J. Buchanan, L. Friedrich, The impact of digital tools on student (Nova, New York, 2003)

5. B. Reeves, C. Nass, The media equation (Georgetown University Press, Washington, 2008)

6. E. A. Shaturnaya, Methods of teaching foreign language professional discourse by means of training-speech situations and roleplaying. (Education, Tambov, 2009)

7. V. L. Tinio, ICT in Education (Pearson, Singapore, 2002)

8. C. C. Tu, P. C. Chen and M.Y. Lee, WHAMPOA, 53, 10 (2007)

9. B. L. Youngs, L. Ducate, N. Arnold, Present and future promises of CALL: From theory and research to new directions in language teaching (CALICO Publications, San Marcos, 2011) 